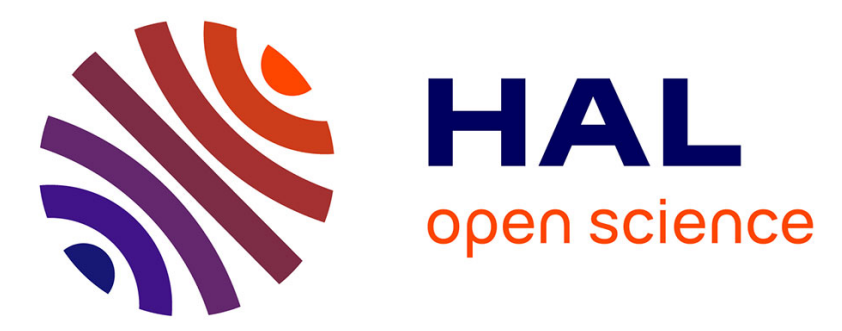

\title{
Water Saturation Computation from Laboratory 3d Regression
}

\author{
G. M. Hamada, M. N.J. Al-Awad, A. A. Alsughayer
}

\section{To cite this version:}

G. M. Hamada, M. N.J. Al-Awad, A. A. Alsughayer. Water Saturation Computation from Laboratory 3d Regression. Oil \& Gas Science and Technology - Revue d'IFP Energies nouvelles, 2002, 57 (6), pp.637-651. 10.2516/ogst:2002044 . hal-02043978

\section{HAL Id: hal-02043978 https://hal.science/hal-02043978}

Submitted on 21 Feb 2019

HAL is a multi-disciplinary open access archive for the deposit and dissemination of scientific research documents, whether they are published or not. The documents may come from teaching and research institutions in France or abroad, or from public or private research centers.
L'archive ouverte pluridisciplinaire HAL, est destinée au dépôt et à la diffusion de documents scientifiques de niveau recherche, publiés ou non, émanant des établissements d'enseignement et de recherche français ou étrangers, des laboratoires publics ou privés. 


\title{
Water Saturation Computation from Laboratory, 3D Regression
}

\author{
G.M. Hamada ${ }^{1}$, M.N.J. Al-Awad ${ }^{1}$ and A.A. Alsughayer ${ }^{1}$ \\ 1 Petroleum Engineering Department, College of Engineering, King Saud University, Saudi Arabia, \\ e-mail: ghamada@ksu.edu.sa - malawwad@ksu.edu.sa - asughayer@ksu.edu.sa
}

\begin{abstract}
Résumé - Estimation de la saturation en eau au laboratoire par régression 3D — La détermination précise des réserves initiales d'un réservoir est très importante pour obtenir une bonne estimation de la capacité de production d'un gisement d'hydrocarbures. La formule modifiée d'Archie $\left(S_{w}=\left(a R_{w} / \phi^{m} R_{t}\right)^{1 / n}\right)$ constitue l'équation de base au calcul de la saturation en eau dans le sable ou l'utilisation d'un modèle de saturation pour le sable argileux. Une bonne évaluation de la saturation en eau dépend de la détermination la plus précise possible des paramètres d'Archie $a, m, n$.

Cet article presente une nouvelle technique destinée à déterminer les paramètres $a, m, n \mathrm{~d}$ 'Archie. Cette technique est basée sur le principe de régression en $3 \mathrm{D}$. Elle surmonte le problème de l'incertitude des valeurs de saturation en eau.

Deux exemples de terrain sont présentés afin de bien tester les résultats de la technique de régression 3D et les comparer à trois autres techniques - méthode CAPE (Core Archie-Parameters Estimation) méthode conventionnelle et valeurs par défaut - concernant les valeurs des paramètres $a, m$ and $n$ de la formule d'Archie et de la saturation en eau.
\end{abstract}

\footnotetext{
Abstract - Water Saturation Computation from Laboratory, 3D Regression - An accurate determination of initial oil in place in the early life of reservoirs or an evaluation of a developed reservoir is required to well estimate the hydrocarbon volumes. Modified Archie's formula $\left(S_{w}=\left(a R_{w}\right)\right.$ $\left.\left.\phi^{m} R_{t}\right)^{1 / n}\right)$ is the basic equation to compute water saturation in clean formation or suitable shaly water saturation model in shaly formation. The accuracy of water saturation value for given reservoir conditions depends on the accuracy of Archie's parameters $a, m$ and $n$. The terms of Archie's relationship have been subjected to many laboratory investigations and even more speculations. There are many factors affecting porosity exponent, $m$, saturation exponent, $n$ and tortuosity factor, $a$. Therefore, it is very difficult to fix Archie's parameters and neglecting reservoir characteristics such as rock wettability, formation water salinity, permeability, porosity and fluids distribution.

This paper presents a new technique to determine Archie's parameters $a, m$ and $n$. The developed technique is based on the concept of three dimensional-regression (3D) plot of water saturation, formation resistivity and porosity. This $3 D$ technique provides simultaneous values of Archie's parameters. Also, the $3 D$ technique overcomes the uncertainty problems due to the separate use of formation resistivity factor-porosity and water saturation equations to get $a, m$ and $n$ parameters.

Two field examples are given to show the applicability of the $3 D$ technique in comparison with three other techniques:

- common values of Archie's parameters,

- conventional technique and

- Core Archie-Parameter Estimation (CAPE) technique.
} 
The comparison among the four techniques has shown that $3 D$ technique provides an accurate and physically meaningful way to get Archie's parameters $a, m$ and $n$ for given core samples. Water saturation profiles, using Archie's parameters obtained from the four techniques, have been obtained for the studied section in the wells. These profiles have shown a significant difference in water saturation values. This difference could be mainly attributed to the uncertainty level for Archie's parameters from each technique. The effect of saturation exponent on the accuracy of water saturation computation was tested using Archie's parameters derived from conventional technique and $3 D$ technique in the two wells.

\section{NOMEN CLATURE}

$a=$ tortuosity factor

$m=$ cementation factor

$n=\quad$ saturation exponent

$S_{w}=$ water saturation, fraction

$V_{\text {sh }}=$ shale volume, $\Omega \cdot \mathrm{m}$

$R_{s h}=$ shale resistivity

$G R=$ gamma ray reading, API

$R_{t}=$ resistivity of rock, $\Omega \cdot \mathrm{m}$

$R_{w}=$ resistivity of brine, $\Omega \cdot \mathrm{m}$

$R_{o}=\quad$ resistivity of rock with $S_{w}=1.0, \Omega \cdot \mathrm{m}$

$I_{r}=$ resistivity index

$F=$ formation resistivity factor

$\phi=$ formation porosity, fraction

$\sigma_{S w}=$ standard deviation in water saturation.

\section{IN TRO DUCTIO N}

In routine formation evaluation Archie's parameters $a, m$ and $n$ are held constant for a given sample of a reservoir rock. In effect, this presumed constancy formulates the basis for the determination of hydrocarbon saturation from resistivity measurements for a particular lithology. An increasing number of cases are being encountered where the saturation exponent, $n$, has been observed to vary from the common value of 2 in strongly water wet reservoir rocks to 25 in strongly oil wet reservoir rocks. Wettability effects become important when brine saturation lowered. Field experience has also shown that the cementation factor, $m$, and the tortuosity factor, $a$, depend on the petrophysical and mechanical properties of a rock [1-3].

Petroleum literature presents an exhaustive review of the results determining Archie's parameters and also water saturation computation processes. In quantitative log interpretation, accurate water saturation requires good values of Archie's parameters. These parameters are used either in Archie's saturation equation in clean formation or in a shaly sand water saturation model in shaly formation.

In this paper, the authors propose a new technique to determine Archie's parameters, three dimensional regression (3D) technique which is based on the analytical expression of 3D plot of $R_{t} / R_{w}$ versus $S_{w}$ and $\phi$. Water saturation profiles are calculated using common values $(1,2,2)$, conventional, CAPE and 3D techniques for selected two wells. In the case of clean sands, Archie formula was used to compute water saturation. In the case of shaly sand sections three shaly sand models were applied and the chosen water saturation was an average value of the three models used.

\section{CALCULATION OF ARCHIE'S PARAMETERS}

An exact computation of water saturation using Archie's formula is based on an accurate values of Archie's parameters $a, m$ and $n$. In this study, 10 clean sand core samples were selected for wells A and B. For each core sample, the electrical resistivity $R_{o}$ at $100 \%$ water saturation and $R_{t}$ at different water saturation percentages were measured at room temperature. The resistivity of simulated brine was fixed at $0.12 \Omega \cdot \mathrm{m}$. This resistivity value corresponds to formation water resistivity $0.054 \Omega \cdot \mathrm{m}$ at reservoir temperature.

Table 1 shows the values of formation resistivity factor $F,\left(R_{o} / R_{w}\right)$ and porosity for 10 core samples of well A and well $\mathrm{B}$. Table 2 contains the measured water saturation for well $\mathrm{A}$ and well $\mathrm{B}$. The average water saturation value for well A was $30.5 \%$ and for well B was $12.25 \%$. These

TABLE 1

Formation resistivity factor, $F$ and porosity, $\phi$ for 10 core samples

Well A

\begin{tabular}{|c|c|c|c|c|c|c|c|c|c|c|}
\hline $\begin{array}{l}F \\
\phi\end{array}$ & $\begin{array}{l}17.8 \\
28.2\end{array}$ & $\begin{array}{l}14.4 \\
31.3\end{array}$ & $\begin{array}{c}10 \\
37.4\end{array}$ & $\begin{array}{l}11.3 \\
35.1\end{array}$ & $\begin{array}{l}10.9 \\
35.9\end{array}$ & $\begin{array}{l}9.5 \\
38\end{array}$ & $\begin{array}{l}22.7 \\
0.25\end{array}$ & $\begin{array}{l}16.8 \\
0.29\end{array}$ & $\begin{array}{l}10.2 \\
36.9\end{array}$ & $\begin{array}{l}11.5 \\
34.5\end{array}$ \\
\hline \multicolumn{11}{|c|}{ Well B } \\
\hline $\begin{array}{l}F \\
\phi\end{array}$ & $\begin{array}{c}35 \\
14.2\end{array}$ & $\begin{array}{c}11 \\
26.7\end{array}$ & $\begin{array}{l}12.7 \\
24.6\end{array}$ & $\begin{array}{c}34 \\
14.3\end{array}$ & $\begin{array}{c}14.5 \\
23\end{array}$ & $\begin{array}{l}12.7 \\
25.4\end{array}$ & $\begin{array}{l}10.5 \\
27.2\end{array}$ & $\begin{array}{c}9.1 \\
30.2\end{array}$ & $\begin{array}{c}9.5 \\
28.5\end{array}$ & $\begin{array}{c}6.4 \\
35.6\end{array}$ \\
\hline
\end{tabular}


TABLE 2

Laboratory measured water saturation of 10 especially preserved core samples

\section{Well A}

\begin{tabular}{|c|c|c|c|c|c|c|c|c|c|c|}
\hline $\begin{array}{c}\text { Sample } \\
S_{w}\end{array}$ & $\begin{array}{c}1 \\
33\end{array}$ & $\begin{array}{c}2 \\
29.5\end{array}$ & $\begin{array}{c}3 \\
28.5\end{array}$ & $\begin{array}{c}4 \\
33\end{array}$ & $\begin{array}{c}5 \\
31.5\end{array}$ & $\begin{array}{c}6 \\
30.5\end{array}$ & $\begin{array}{c}7 \\
31\end{array}$ & $\begin{array}{c}8 \\
29\end{array}$ & $\begin{array}{c}9 \\
31\end{array}$ & $\begin{array}{l}10 \\
28\end{array}$ \\
\hline \multicolumn{11}{|c|}{ Average water saturation $=30.5 \%$. } \\
\hline \multicolumn{11}{|c|}{ Well B } \\
\hline $\begin{array}{c}\text { Sample } \\
S_{w}\end{array}$ & $\begin{array}{c}1 \\
13\end{array}$ & $\begin{array}{c}2 \\
10.5\end{array}$ & $\begin{array}{c}3 \\
12\end{array}$ & $\begin{array}{c}4 \\
11.5\end{array}$ & $\begin{array}{c}5 \\
13\end{array}$ & $\begin{array}{c}6 \\
12.5\end{array}$ & $\begin{array}{c}7 \\
10.5\end{array}$ & $\begin{array}{c}8 \\
12\end{array}$ & $\begin{array}{c}9 \\
13\end{array}$ & $\begin{array}{c}10 \\
14.5\end{array}$ \\
\hline
\end{tabular}

Average water saturation $=12.25 \%$.

TABLE 3

Electrical resistivity, $R_{t}$; resistivity index, $I_{r}$; fractional water saturation, $S_{w}$; and core sample porosity, $\phi$ for 6 core samples from well A and well B

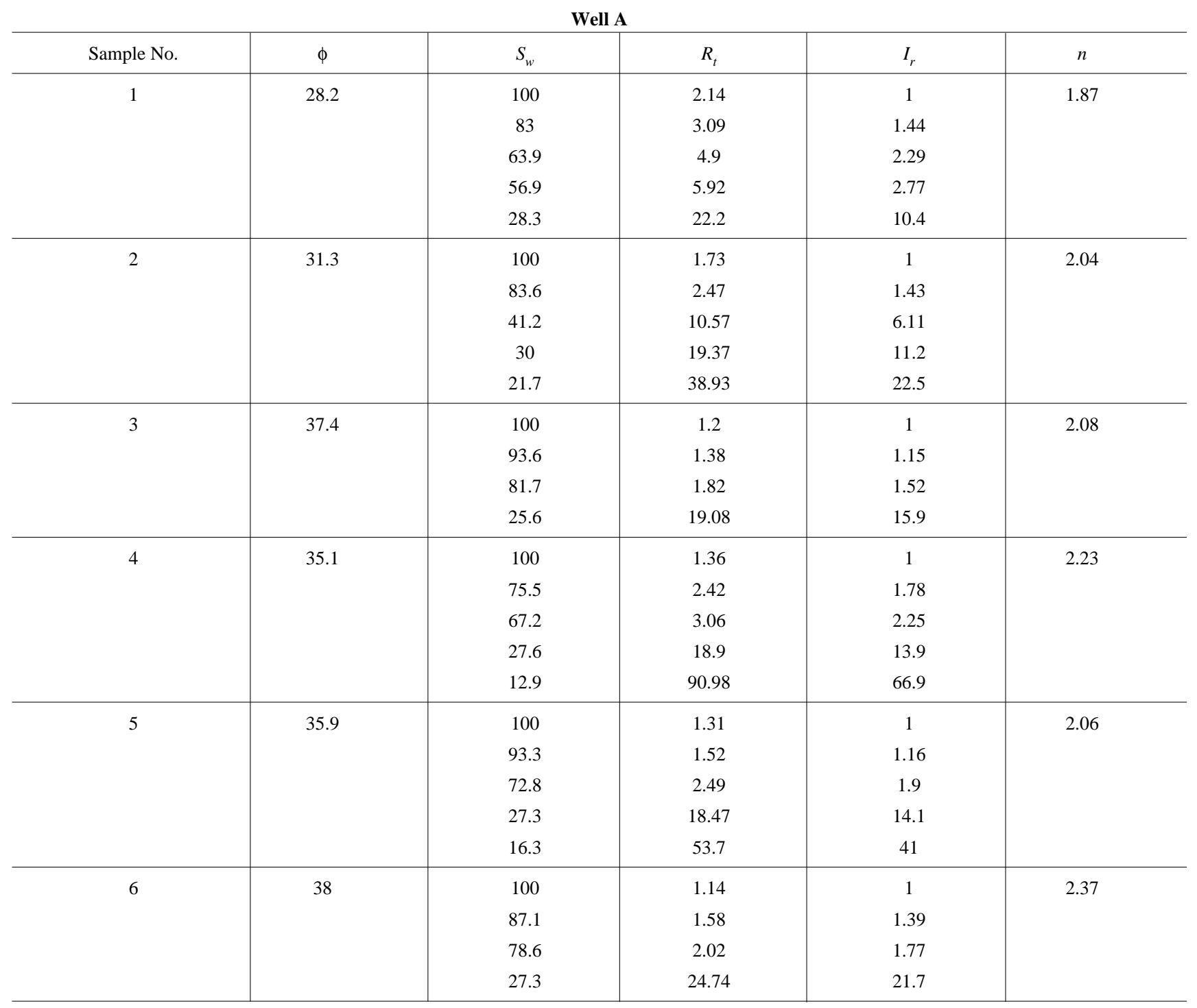

Average saturation exponent, $n=2.1$. 
TABLE 3 (continued)

Electrical resistivity, $R_{t}$; resistivity index, $I_{r}$; fractional water saturation, $S_{w}$; and core sample porosity, $\phi$ for 6 core samples from well A and well B

\begin{tabular}{|c|c|c|c|c|c|}
\hline \multicolumn{6}{|c|}{ Well B } \\
\hline Sample No. & $\phi$ & $S_{w}$ & $R_{t}$ & $I_{r}$ & $n$ \\
\hline \multirow[t]{6}{*}{1} & \multirow[t]{6}{*}{14.2} & 100 & 4.2 & 1 & 2.17 \\
\hline & & 71.1 & 8.81 & 2.09 & \\
\hline & & 66.6 & 10.11 & 2.41 & \\
\hline & & 55.4 & 15.16 & 3.61 & \\
\hline & & 40.8 & 28.74 & 6.84 & \\
\hline & & 35.9 & 38.18 & 9.09 & \\
\hline \multirow[t]{6}{*}{2} & \multirow[t]{6}{*}{26.7} & 100 & 1.32 & 1 & 1.88 \\
\hline & & 57 & 3.78 & 2.86 & \\
\hline & & 25.3 & 17.36 & 13.15 & \\
\hline & & 16.3 & 39.84 & 30.18 & \\
\hline & & 15.9 & 40.88 & 31 & \\
\hline & & 15 & 47.60 & 36.06 & \\
\hline \multirow[t]{6}{*}{3} & \multirow[t]{6}{*}{24.6} & 100 & 1.52 & 1 & 2.09 \\
\hline & & 90.2 & 1.91 & 1.26 & \\
\hline & & 73.3 & 3.24 & 2.13 & \\
\hline & & 35.5 & 12.98 & 8.54 & \\
\hline & & 25 & 28.04 & 18.45 & \\
\hline & & 24.5 & 29.17 & 19.19 & \\
\hline \multirow[t]{6}{*}{4} & \multirow[t]{6}{*}{14.3} & 100 & 4.08 & 1 & 2.37 \\
\hline & & 77.1 & 7.52 & 1.84 & \\
\hline & & 45.2 & 26.6 & 6.52 & \\
\hline & & 40 & 34.87 & 8.55 & \\
\hline & & 36.9 & 42.41 & 10.39 & \\
\hline & & 35.9 & 45.32 & 11.11 & \\
\hline \multirow[t]{6}{*}{5} & \multirow[t]{6}{*}{25.2} & 100 & 1.46 & 1 & 2.12 \\
\hline & & 75.5 & 2.66 & 1.78 & \\
\hline & & 52.3 & 5.78 & 3.96 & \\
\hline & & 26.2 & 24.75 & 16.95 & \\
\hline & & 21.5 & 39 & 26.71 & \\
\hline & & 21.1 & 40 & 27.39 & \\
\hline \multirow[t]{6}{*}{6} & \multirow[t]{6}{*}{23} & 100 & 1.74 & 1 & 2.53 \\
\hline & & 40.9 & 16.46 & 9.46 & \\
\hline & & 39.4 & 18.55 & 10.66 & \\
\hline & & 29.8 & 36.65 & 21.01 & \\
\hline & & 19.9 & 99 & 56.89 & \\
\hline & & 19.3 & 110 & 63.21 & \\
\hline
\end{tabular}

Average saturation exponent, $n=2.19$. 
laboratory water saturation values have been used in calculating Archie's parameters while the average values were being taken as references for the computed water saturation values from logging data with the use Archie's parameters by different techniques. Table 3 illustrates core sample resistivity, $R_{t}$ at different water saturation, resistivity index, $I_{r}$, porosity, $\phi$ for 6 core samples from wells A and $\mathrm{B}$. Using the same specially preserved core samples, the water saturation has been measured in the laboratory.

\subsection{Conventional Determination of $a, m$ and $n$}

In 1942, Archie proposed an empirical relationship between rock resistivity, $R_{t}$, with its porosity, $\phi$, and water saturation $S_{w}$.

$$
S_{w}^{n}=a R_{w} / \phi^{m} R_{t}=R_{o} / R_{t}=1 / I_{r}
$$

Other terms $I_{r}, m$, and $n$ represent the resistivity index, the cementation factor and the saturation exponent. He has also shown experimentally that the resistivity of rock fully saturated with brine, $R_{o}$, is related to the brine resistivity, $R_{w}$, by:

$$
R_{o}=F R_{w}
$$

where $F$ is formation resistivity factor. Archie's formula $(F=$ $\left.1 / \phi^{m}\right)$ has been modified and tortousity factor, $a$, was added to Archie's formula [4]. It has taken the following form:

$$
F=a / \phi^{m}
$$

\subsubsection{Conventional Determination of a and $\mathrm{m}$}

The conventional determination of $a$ and $m$ is based on Equation (3) and is rewritten as:

$$
\log F=\log a-m \log \phi
$$

Plot of $\log F v s . \log \phi$ is used to determine $a$ and $m$ for the core samples. The cementation factor $m$, is determined from the slope of the least square fit straight line of the plotted points, while the tortuosity factor is given from the intercept of the line where $\phi=1$. Note that, in this plot, only points of $S_{w}=1.0$ is used. Archie's parameters $a$ and $m$ were determined as 1.36 and 2.03 for well $\mathrm{A}$ and 0.95 and 1.85 for well B.

\subsubsection{Conventional Determination of $n$}

The classical process to determine saturation exponent $n$ is based on Equation (1). This equation is rewritten as:

$$
\log I_{r}=-n \log S_{w}
$$

The bi-logarithmic plot of $I_{r}$ versus $S_{w}$ gives a straight line with negative slope $n$. Table 3 contains the saturation exponent value for each core sample: this value is determined form the bi-logarithmic plot of $I_{r}$ and $S_{w}$ for each core sample. Sometimes, data are plotted as $\log R_{t} v s . \log S_{w}$. This form is mathematically equivalent to the bi-logarithmic plot of $I_{r}$ and $S_{w}$ and provides the same value of $n$. The retained saturation exponent is the average values of the 6 core samples measurements. The saturation exponent equals to 2.1 for well A and 2.19 for well B. It is obvious that the conventional technique treats the determination of $n$ as a separate problem from $a$ and $m$. This separation is not physically correct, thereby; it induces an error in the value of water saturation using Equation (1).

\subsection{Core Archie-Parameter Estimation (CAPE)}

A data analysis approach is presented in [5] to determine Archie's parameters $m$ and $n$ and optionally $n$ from standard resistivity measurements on core samples. The analysis method, Core Archie-Parameters Estimation (CAPE) determines $m$ and $n$ and optionally $a$ by minimising the error between computed water and measured water saturations. The mean square saturation error $\varepsilon$, is given by:

$$
\varepsilon=\sum_{j} \sum_{i}\left[S_{w i j}-\left(a R_{w i j} / \phi_{i}^{m} R_{t i j}\right)^{1 / n}\right]^{2}
$$

Where $j=$ core index, $i=$ index for each of the core $j$ measurements, $S_{w i j}=i$ th laboratory measured water saturation for core $j$ (fraction), $R_{t i j}=i$ th laboratory measured resistivity for core $j, \Omega \cdot m$, and $\phi_{j}=$ core $j$ porosity (fraction). Equation (6) calculates the minimum error between measured core water saturation and computed water saturation by Archie's formula, by adjusting $m, n$ and optionally $a$ in the equation.

Table 4 illustrates typical results from CAPE and conventional methods and shows $a, m$ and $n$ values calculated with the two methods for clean sandstone core samples. It is obvious that the values of $a, m$ and $n$ are different for a given set of points.

TABLE 4

Archie's parameters values from four techniques for well A and well B

Well A

\begin{tabular}{l|c|c|c}
\hline Technique & $a$ & $m$ & $n$ \\
Common values & 0.65 & 2.15 & 2 \\
Conventional & 1.36 & 2.03 & 2.1 \\
CAPE & 1.64 & 1.87 & 2.21 \\
3D & 1.43 & 1.97 & 2.15 \\
\hline \multicolumn{3}{|c}{ Well B } \\
\hline Technique & $a$ & $m$ & $n$ \\
Common values & 0.65 & 2.15 & 2 \\
Conventional & 0.95 & 1.85 & 2.19 \\
CAPE & 1.04 & 1.79 & 1.95 \\
3D & 0.92 & 1.87 & 1.87
\end{tabular}




\subsection{Three-Dimensional Regression (3D)}

In this technique it is contended that, so far as Archie's parameters are concerned, the error in the water saturation value should be kept minimum. This is because the water saturation quantity is desired and is physically a meaningful quantity. Here, a method is developed to determine Archie's parameters $a, m$ and $n$ using standard resistivity measurements on core samples [6-10].

Methodology: The basis of the 3D technique is to view $S_{w}$ in Archie's formula Equation (1) as a variable in threedimensional regression plot of $S_{w}, R_{w} / R_{t}$ and $\phi$. The 3D technique determines Archie's parameters $a, m$ and $n$ by solving three simultaneous equations of $S_{w}, R_{w} / R_{t}$ and $\phi$. Equation (1) is rearranged after taking the logarithm of both sides in the form:

$$
\log R_{w} / R_{t}=-\log a+m \log \phi+n \log S_{w}
$$

The left hand side of Equation (7) is a dependent variable of the two independent variables $S_{w}$ and $\phi$. Equation (7) is an equation of a plane in 3D space of coordinates $X, Y$ and $Z$ $\left(X=\log \phi, Y=\log S_{w}\right.$ and $\left.Z=\log R_{w} / R_{t}\right)$. The intersection of this plane with the plane $(X=0.0)$ gives a staight line of slope $(m)$, with the plane $(Y=0.0)$ giving a straight line with slope $(n)$ and with the plane $(Z=0.0)$ provides the value of (a) parameter.

For a given set of data for a core sample, we can obtain an equivalent set of variables $X, Y$ and $Z$. Equation (7) will take the following form for $i$ measurement points:

$$
Z_{i}=-A+m X_{i}+n Y_{i}
$$

After normalizing Equation (8) for $N$ readings, the following three simultaneous equations are resulted.

$$
\begin{gathered}
\Sigma Z_{i}=-N A+m \Sigma X_{i}+n \Sigma X_{i} \\
\Sigma X_{i} Z_{i}=-A N \Sigma X_{i}+m \Sigma X_{i}^{2}+n \Sigma X_{i} Y_{i} \\
\Sigma Y_{i} Z_{i}=-A N \Sigma Y_{i}+m \Sigma X_{i} Y_{i}+n \Sigma Y_{i}^{2}
\end{gathered}
$$

The solution of Equations (9-11) provides the values of Archie's parameters $a, m$ and $n$ for one core sample. For $j$ core samples, running the same analysis produces average values of Archie's parameters. Figure 1 illustrates flow chart to compute Archie's parameters by 3D technique for $i$ measurements on $j$ core samples. Table 4 shows Archie's parameters calculated by 3D technique in addition to, CAPE, conventional and common values.

Note that the CAPE method is based on the idea that the two logarithmic plots of $F$ versus $\phi$ and $S_{w}$ versus $I_{r}$ are not the optimum way of handling the problem. The comparison between the two techniques showed that CAPE might not appear as optimal as the conventional method. Instead, we are presenting another approach, the 3D technique. In this technique, water saturation is treated as an independent variable in $3 \mathrm{D}$ plot of electrical resistivity $v s$. water saturation and porosity.

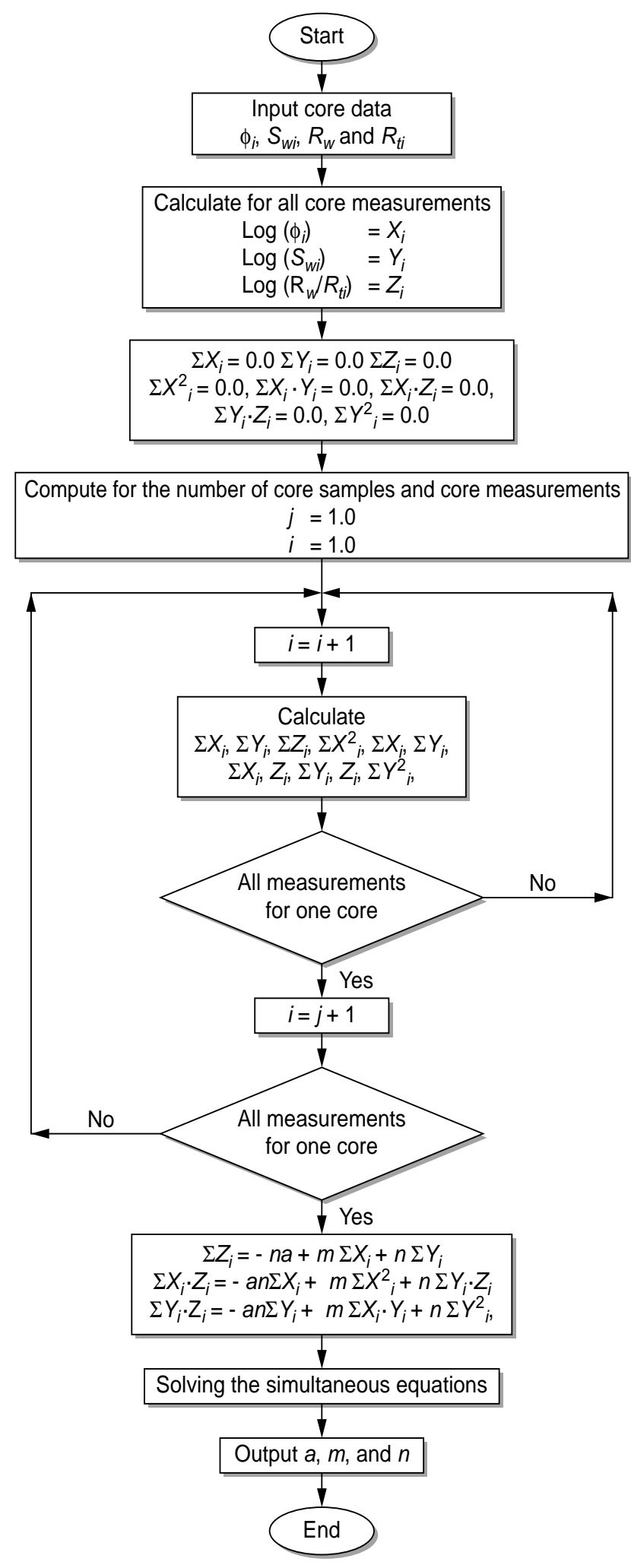

Figure 1

Flow chart to compute Archie's parameters with 3D technique. 


\subsubsection{Assumptions}

First, 3D technique assumes that Archie's formula is applicable to the examined core samples. Also, the core samples represent the zone of interest. For shaly sandstone, Archie's formula must be modified to account for the presence of shale and its effect on resistivity measurements. The user is free to select the appropriate clay model, and consequently, the shaly sand water saturation equation. The second assumption might be difficult to satisfy since it is dealing with the accuracy of the laboratory measurements under reservoir conditions. The third assumption deals with the concept of the 3D technique, this means that the user must be acquainted with the basis and limitations of each method before using it.

\section{APPLICATIONS}

Two field examples are used for applying the calculated Archie's parameters to compute water saturation. Figures 2 and 3 are logging suites of resistivity, neutron, $G R$ and density for wells A and B. $G R$ was used to calculate shale volume ( $V_{s h}=0.33\left(2^{2 * G R}-1\right)$, when $V_{s h}$ is $\leq 0.10$, section is considered clean sand and when $V_{s h}$ is $\geq 0.75$, it is taken as shale section. Neutron and density logs readings have been corrected from shale effect to give corrected porosity values for using either in Archie's formula or in shaly water saturation model. The studied field examples produce from clean sand sections and shaly sand sections. Figure 4 shows flow chart for a computer program used to compute water saturation in clean and shaly sections with the use of Archie's

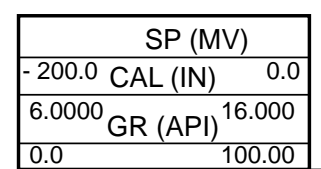

\begin{tabular}{|r}
\hline .200 \\
\hline .200
\end{tabular} \begin{tabular}{|lll|}
\hline & & \\
\hline & $\operatorname{MSFL}(\Omega \cdot \mathrm{m})$ \\
\hline 2000 & $\operatorname{ILD}(\Omega \cdot \mathrm{m})$ & 2000.0 \\
.2000 & & 2000.0 \\
\hline
\end{tabular}
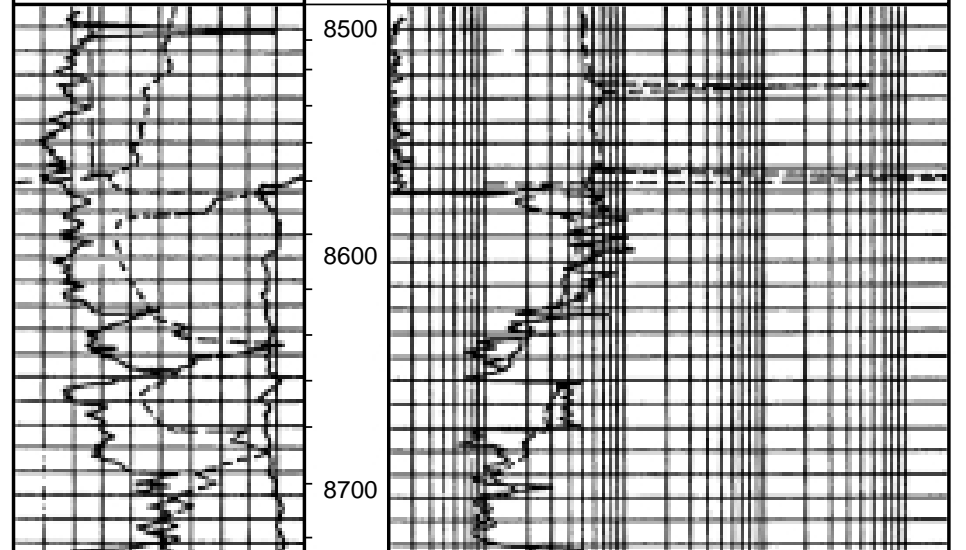

8600
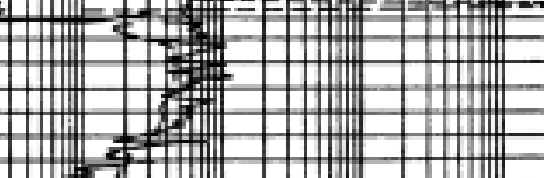

更
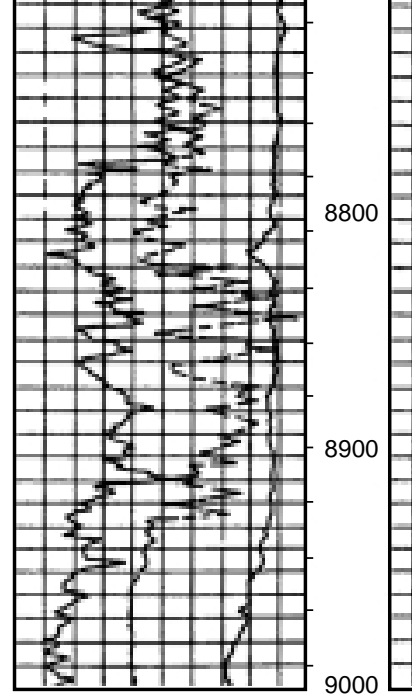

8800

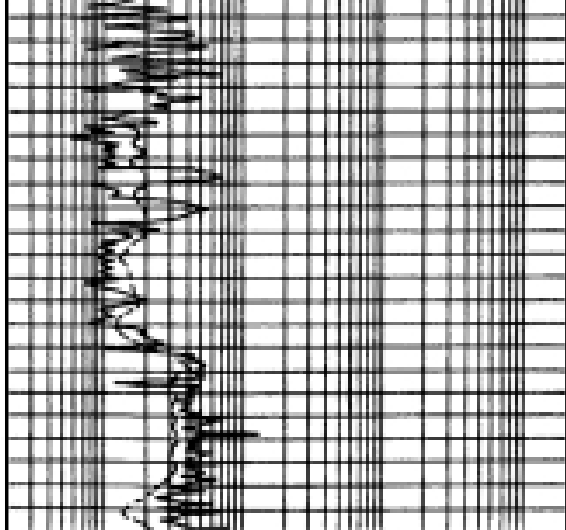

9000

\begin{tabular}{|c|c|c|}
\hline$=-\frac{D P}{050}$ & $\left.\mathrm{G} / \mathrm{C}^{3}\right)$ & \\
\hline$\frac{.0500}{.45000}$ & .45000 & $\mathrm{NPHI}$ \\
\hline .45000 & RHOB & $\left(\mathrm{G} / \mathrm{C}^{3}\right)$ \\
\hline
\end{tabular}

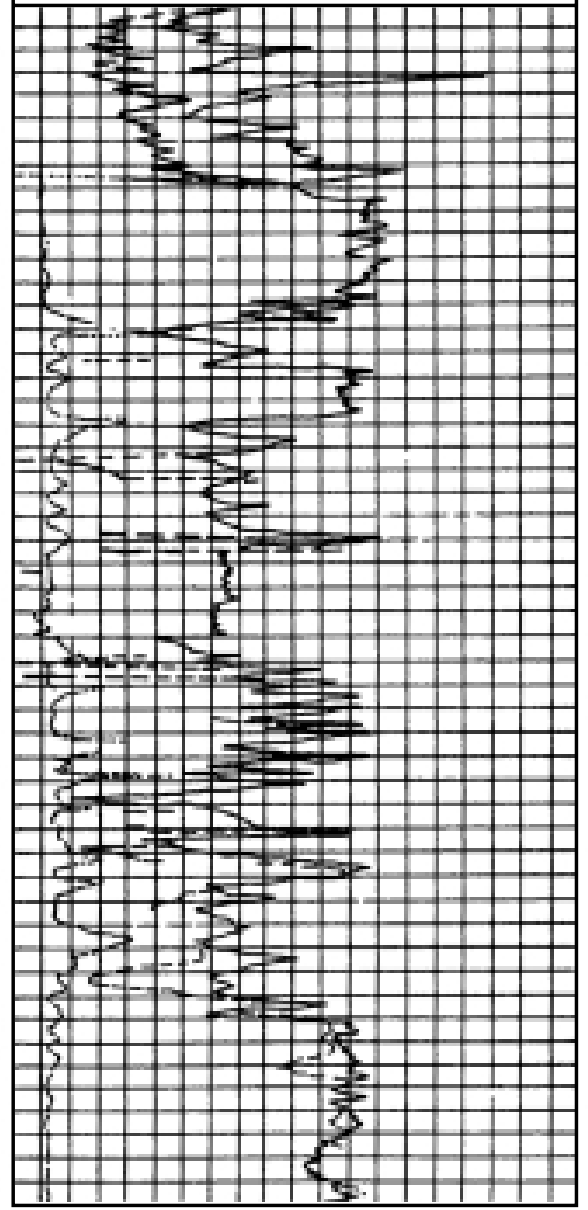

Figure 2

Well logging data for well A. 

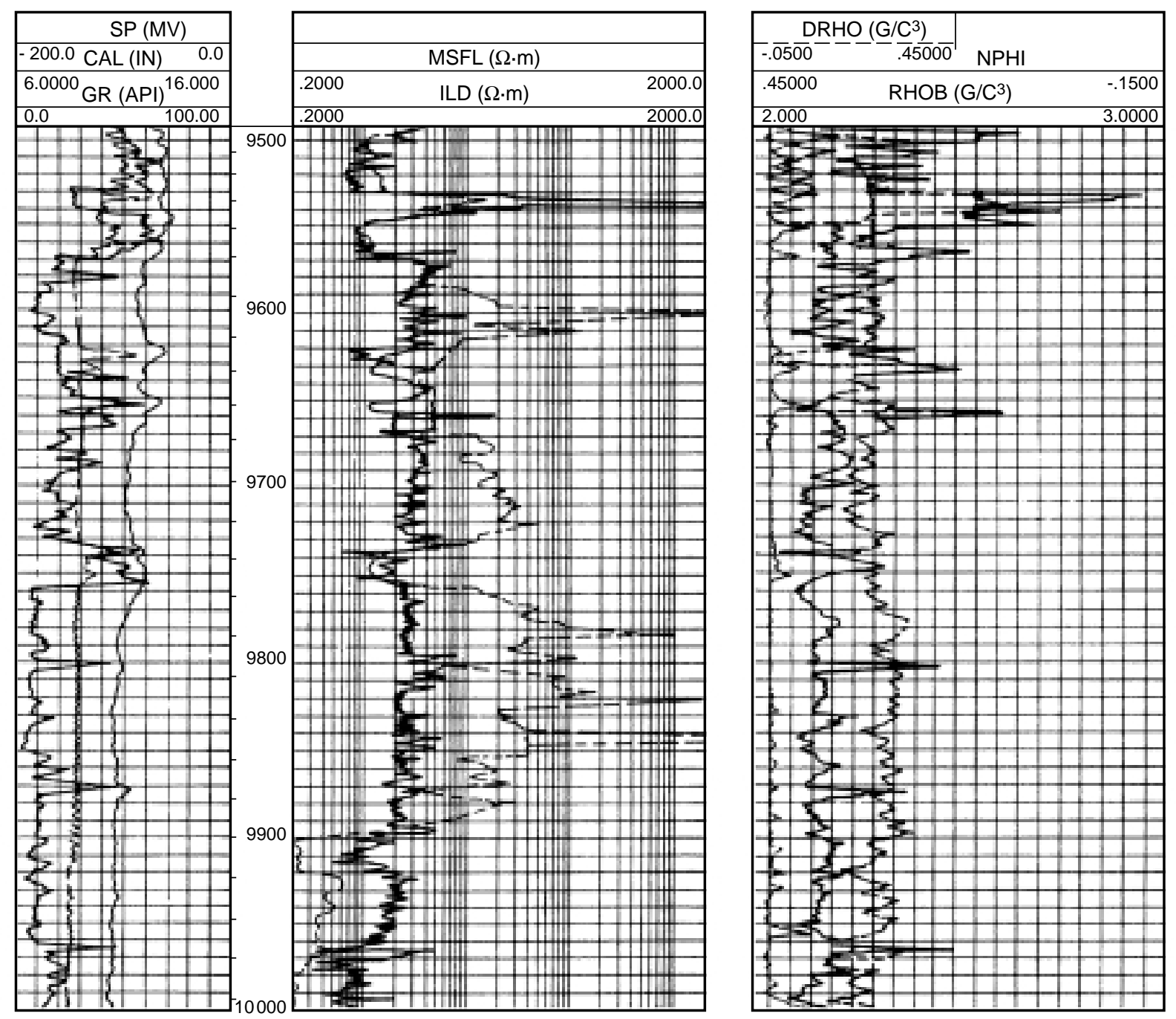

Figure 3

Well logging data for well B.

parameters from each technique: Conventional, CAPE and 3D and also common Archie's parameters for sands ( $a=0.65$, $m=2.15$ and $n=2$ ).

In clean sand, water saturation is computed by Archie's formula:

$$
S_{w}=\left(a R_{w} / \phi^{m} R_{t}\right)^{1 / n}
$$

An accurate computation of water saturation in shaly sand is subjected to many uncertain parameters. It is necessary to integrate the information from several types of $\log$ s using different interpretation models and local experience, in order to accurately determine the desired formation properties. $G R \log$ is used to determine shale volume that has been used to correct density and neutron porosity values from shale effect to give a corrected effective porosity used in water saturation computation. In the analysis program, clean sand is assumed for $V_{s h} \leq 0.10$ and use Archie's formula to find $S_{w}$, shaly sand section is assumed for $0.10 \leq V_{s h} \leq 0.75$ and use shaly sand water saturation model to find $S_{w}$ and shale section is assumed for $V_{s h} \geq 0.75$ and neglect it. Water saturations have been computed for clean sections and shaly sand sections using Archie's parameters calculated by conventional, CAPE, 3D techniques and common values. Repeating the computer program and each time with different Archie's parameters $a, m$ has done this and $n$ values as shown in Figure 4. Considering the fact that water saturation has been computed in high shale volume sections as well as in low shale volume sections, we used three shale models and final water saturation value is taken as the average value of the three shaly sand water saturation models. In effect, clays are dispersed within sand grains and, 


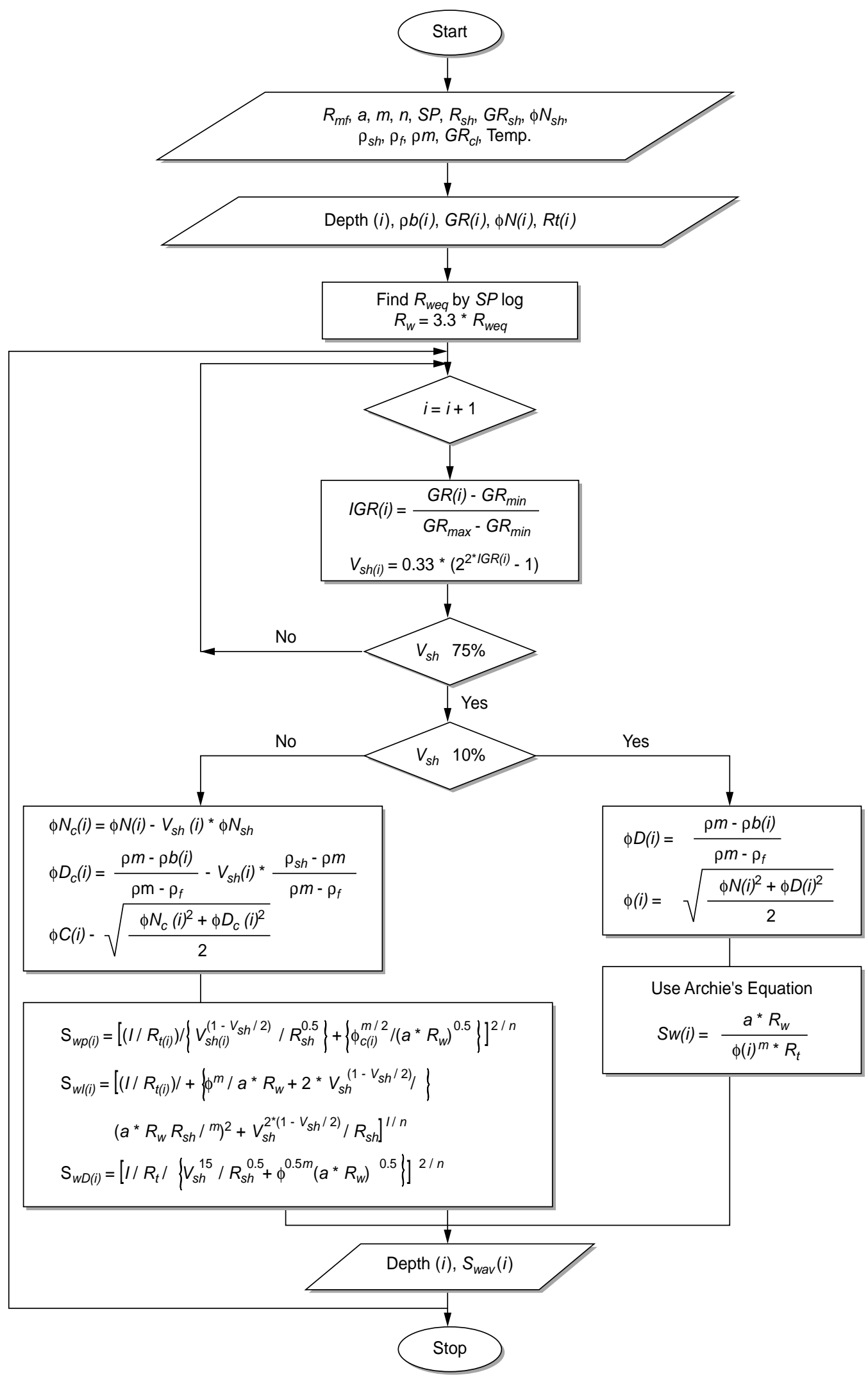

Figure 4

Flow chart to compute water saturation. 
so, we selected three dispersed clay models. In fact that there is no general shaly sand model can be applied in all modes of shale distribution and also at level of shale volume. For example Doll model [11] often gives optimistic results, but in very shaly pay zone can be unrealistic and Poupon et al. [12] model and Hossin model [13] often become pessimistic in shaly pay sand located in transition zones and their application may condemn pay zones of commercial significance.

Consequently, it is recommended in these field examples to compute water saturation by the three models; Poupon et al., Doll and Indonesia [14]. Final water saturation value will be the average value of the calculated water saturations derived from the three models. Water saturation equations of the three models are given as:

Doll model [11]:

$$
S_{w D(i)}=\left[1 / R /\left\{V_{s h}^{1.5} / R_{s h}^{0.5}+\phi^{0.5 m} /\left(a R_{w}\right)^{0.5}\right\}\right]^{2 / n}
$$

Poupon et al. model [12]:

$$
\begin{aligned}
S_{w p(i)} & =\left[\left(1 / R_{t(i)}\right) /\left\{V_{s h(i)}\left(1-V_{s h} / 2\right) / R_{s h} 0.5\right\}\right. \\
& +\left\{\phi_{c(i)} m / 2 /\left(a * R_{w}\right)^{0.5}\right]^{2 / n}
\end{aligned}
$$

Indonesia model [14]:

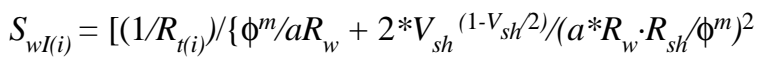

$$
\begin{aligned}
& \left.+V_{s h}^{2 *\left(1-V_{s h} / 2\right)} / R_{s h}\right\}^{1 / n}
\end{aligned}
$$

Figure 5 shows water saturation profiles for well A using Archie's parameters $a, m$ and $n$ calculated by four techniques. Water saturation was computed in clean sand section with Archie's formula while in shaly sand section it was computed using shaly sand water saturation models. Water saturation has been measured in the laboratory on 10 core samples from the studied section in the well; the average water saturation of all core samples was $30.5 \%$. Figure 5a illustrates water saturation profile with depth using common values ( $a=0.65, m=2.15$ and $n=2$ ). Examination of Figure 5a shows that water saturation is generally high and the average water saturation for 85 points was $34.4 \%$ with standard deviation $\left(\sigma_{S_{w}}\right)$ values equals to 0.34 . Figure $5 \mathrm{~b}$ is the water saturation profile versus depth with use of Archie's parameters calculated by conventional technique $(a=1.36$, $m=2.03$ and $n=2.1$ ). The average water saturation of the studied section of 85 points was $47 \%$ with standard deviation $\left(\sigma_{S_{w}}\right)=0.17$. It is still high, but it is better than in the case of
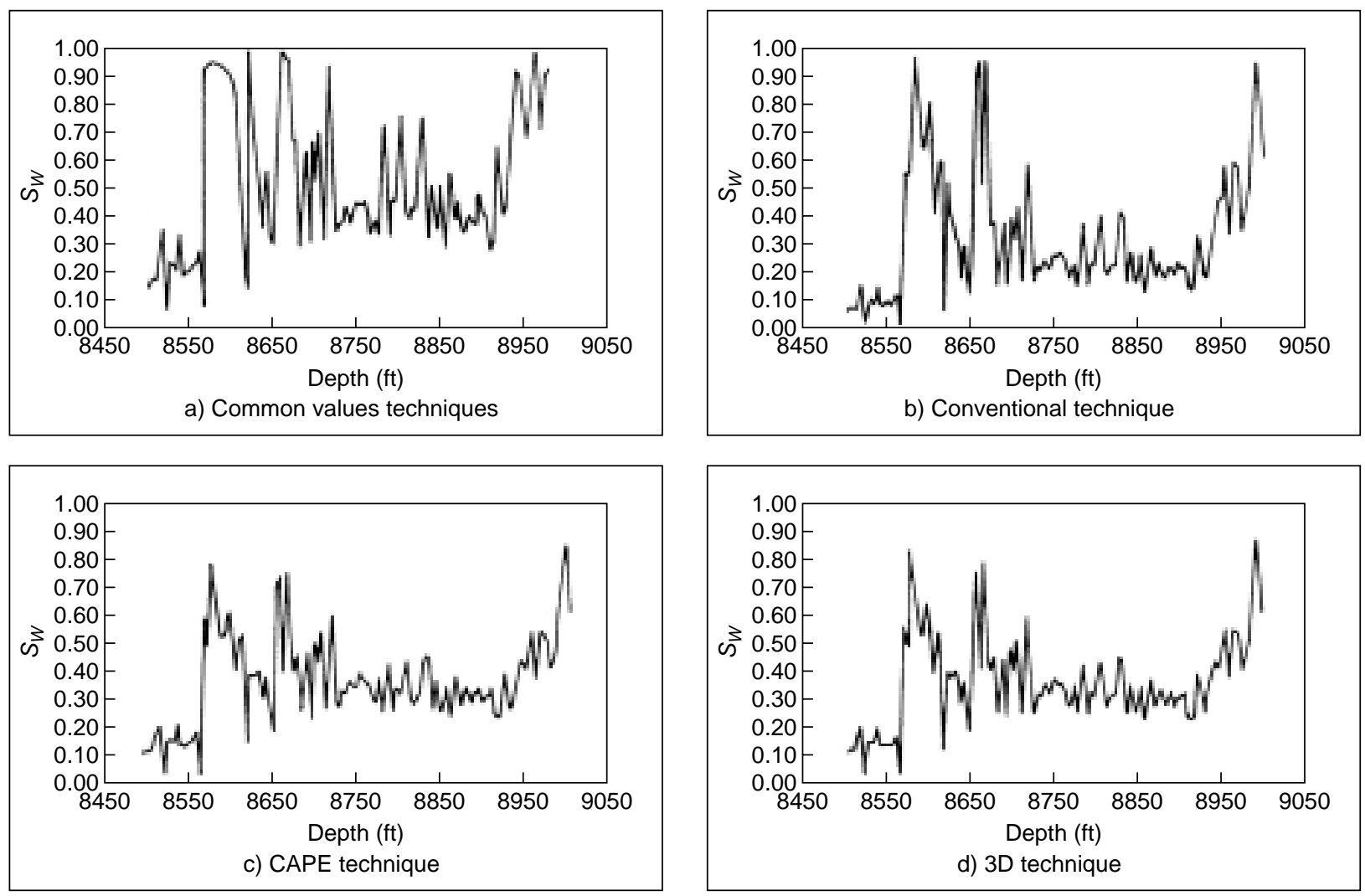

Figure 5

Water saturation profiles with different Archie's parameters using four techniques for well A. 
common values. Figure $5 \mathrm{c}$ shows water saturation profile derived from water saturation equations using Archie's parameters calculated by using the CAPE technique $(a=$ $3.21, m=1.7$ and $n=2.21$ ). The average water saturation of the retained section was about $28 \%$ with standard deviation $\left(\sigma_{S_{w}}\right)=0.067$. CAPE technique provided water saturation value much closer to the average value of core-measured water saturation $\left(S_{w c o r e}=30.5 \%\right)$ than conventional and common techniques. Figure $5 \mathrm{~d}$ depicts the water saturation profile deduced from the use of Archie's parameters calculated by 3D technique ( $a=2.94, m=1.56$ and $n=2.15$ ). Average value of 85 water saturation points was found $31.2 \%$. With standard deviation $\left(\sigma_{S_{w}}\right)$ equals to 0.069 . Table 5 summarises the average water saturation values computed by the Archie's parameters deduced from the three techniques. It is obvious that CAPE and 3D methods give water saturation more accurate than the other methods and also with lower standard deviation error. The 3D technique seems better than CAPE due to lower computing time and by its optimisation technique which is more physically concerned with water saturation and related factors than CAPE technique.

TABLE 5

Average water saturation and standard deviations using Archie's parameters from four techniques for well $\mathrm{A}$ and well B

Well A

\begin{tabular}{|c|c|c|}
\hline Technique & $S_{w}$ & $\sigma_{w}$ \\
\hline Common values & 34.4 & 0.34 \\
\hline Conventional & 47 & 0.17 \\
\hline CAPE & 28 & 0.067 \\
\hline $3 \mathrm{D}$ & 31.2 & 0.069 \\
\hline \multicolumn{3}{|c|}{ Well B } \\
\hline Technique & $S_{w}$ & $\sigma_{w}$ \\
\hline Common values & 10.2 & 0.38 \\
\hline Conventional & 15.4 & 0.19 \\
\hline CAPE & 6.5 & 0.072 \\
\hline $3 \mathrm{D}$ & 11.6 & 0.078 \\
\hline
\end{tabular}
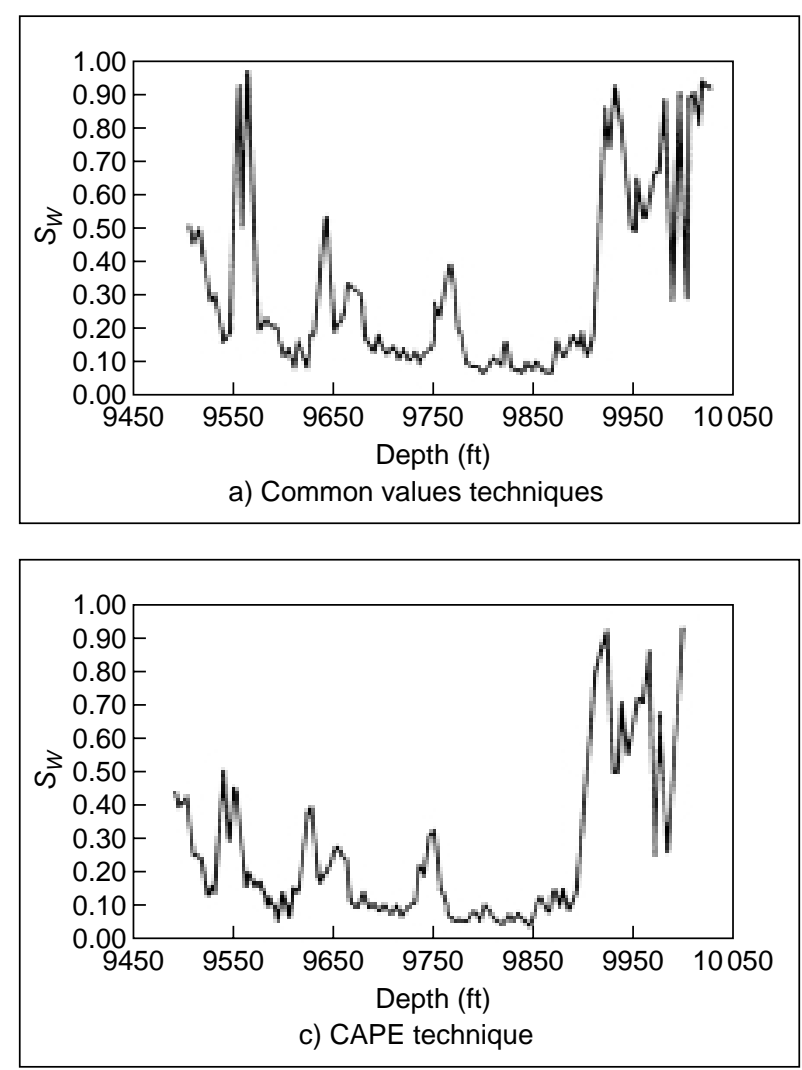
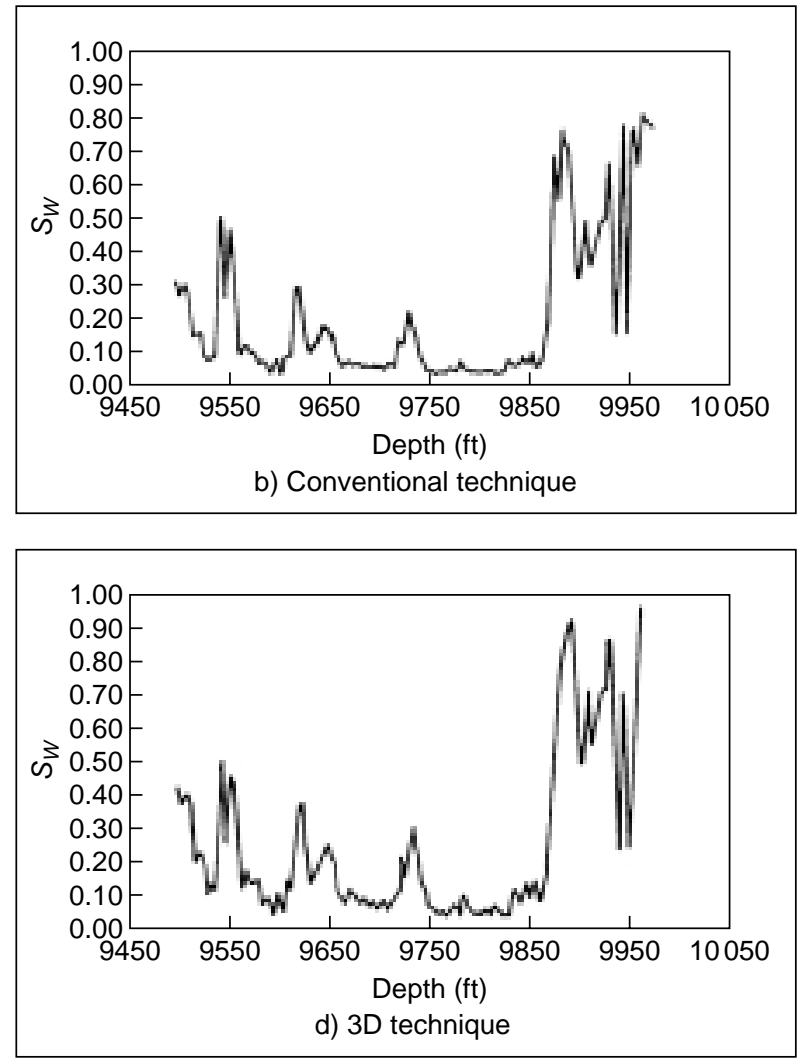

Figure 6

Water saturation profiles with different Archie's parameters using four techniques for well B. 
Figure 6 shows water saturation profiles for well B deduced from different water saturation equations (Archie's water saturation equation in the case of clean sand and shaly water saturation equations in the case of shaly sand sections, 10 core samples) measurements that give an average water saturation of $12.25 \%$. Figure 6 a shows water saturation versus depth, the Archie's parameters used to compute water saturation with the common values $(a=0.65, m=2.15$ and $n=2)$. Using 85 saturation points, the average water saturation was $10.5 \%$ with standard deviation $\left(\sigma_{S_{w}}\right)=0.38$. Water saturation profile with Archie's parameters derived by the conventional technique ( $a=0.95, m=1.85$ and $n=2.12$ ) is shown in Figure $6 \mathrm{~b}$. The average value of an 85 saturation points of this curve was in the range of $15.4 \%$ with standard deviation $\left(\sigma_{S_{w}}\right)=0.19$. This reflects that water saturation calculated by conventional is much better than that derived from common Archie's parameters. Figure 6c illustrates the water saturation curve determined after the use of CAPE technique to Archie's parameters ( $a=2.44, m=1.2$ and $n=$ 1.95). Examination of this water saturation profile shows that water saturation values are low with an average of $6.5 \%$ and standard deviation $\left(\sigma_{S_{w}}\right)=0.072$. This average value is much less than core sample water saturation value. Figure 6d shows water saturation profile with the use of Archie's parameters computed by 3D technique $(a=2.59, m=1.43$ and $n=1.87$ ). The average water saturation of 85 saturation points was found $11.6 \%$ and their standard of deviation was 0.078. The average water saturation values using Archie's parameters calculated by the different techniques are presented in Table 5. It is clear that 3D technique gives better standard deviation and the closest average saturation to the core samples measured water saturation value. Therefore it is recommended to use the $3 \mathrm{D}$ technique which provides the values of Archie's parameters $a, m$ and $n$ and with an accepted water saturation error.

\section{VARIABLE SATURATION EXPONENT AND WATER SATURATIO N}

Laboratory measured saturation exponent $(n)$ showed some variations. An exact value of saturation exponent is necessary for a good $\log$ interpretation analysis aiming to a precise water saturation determination. There are many factors affecting saturation exponent such as rock wettability, grain pattern, presence of certain authigenic clays, particulary chamosite, which may promote oil wet characteristics and history of fluid displacement. However, it is found that rock wettability is the main factor affecting saturation exponent (n). Archie's saturation equation makes three implicit assumptions:

- the saturation/resistivity relation is unique;

- $n$ is constant for a given porous medium;

- all brine contributes in the electric current flow.
It has been found [8] that these assumptions are valid only in water-wet reservoir. This is because the saturation exponent $n$ depends on the distribution of the conducting phase in the porous medium and therefore depends on the wettability. The saturation exponent $(n)$ is about 2 in waterwet rock, where brines spread over grain surface and facilitate the flow of the electric current. While it may reach 25 in strongly oil-wet rock, where oil coats grain surface and causes disconnections and isolation of globules of brine and therefore this brine will be unable to conduct a current flow.

TABLE 6

Change of water saturation with saturation exponent for well A and well B

A - Common values technique Well A

\begin{tabular}{|c|c|c|c|c|}
\hline $\begin{array}{l}n \\
S_{w}\end{array}$ & $\begin{array}{c}2 \\
0.344 \\
\end{array}$ & $\begin{array}{c}4 \\
0.676 \\
\end{array}$ & $\begin{array}{c}6 \\
0.781 \\
\end{array}$ & $\begin{array}{c}8 \\
0.825 \\
\end{array}$ \\
\hline \multicolumn{5}{|c|}{ Well B } \\
\hline $\begin{array}{l}n \\
S_{w}\end{array}$ & $\begin{array}{c}2 \\
0.154 \\
\end{array}$ & $\begin{array}{c}4 \\
0.367 \\
\end{array}$ & $\begin{array}{c}6 \\
0.510 \\
\end{array}$ & $\begin{array}{c}8 \\
0.601 \\
\end{array}$ \\
\hline \multicolumn{5}{|c|}{$\begin{array}{c}\text { B - 3D technique } \\
\text { Well A }\end{array}$} \\
\hline $\begin{array}{l}n \\
S_{w}\end{array}$ & $\begin{array}{c}2.15 \\
0.312 \\
\end{array}$ & $\begin{array}{c}4 \\
0.641 \\
\end{array}$ & $\begin{array}{c}6 \\
0.745\end{array}$ & $\begin{array}{c}8 \\
0.811 \\
\end{array}$ \\
\hline \multicolumn{5}{|c|}{ Well B } \\
\hline $\begin{array}{l}n \\
S_{w}\end{array}$ & $\begin{array}{c}1.87 \\
0.116\end{array}$ & $\begin{array}{c}4 \\
0.378 \\
\end{array}$ & $\begin{array}{c}6 \\
0.521 \\
\end{array}$ & $\begin{array}{c}8 \\
0.621 \\
\end{array}$ \\
\hline
\end{tabular}

In order to test the effect of saturation exponent on water saturation computation, parameters $a$ and $m$ were fixed and $n$ took different values 2, 4, 6 and 8 in the case of common values technique and values of 1.87, 2.15, 4, 6 and 8 in using 3D technique for wells A and B. From experience, saturation exponents $1.87,2,2.15$ correspond to water wet rock assumption and saturation exponents 4, 6 and 8 indicate preferably oil-wet rock. Water saturation was computed using the same 85 saturation points for well $\mathrm{A}$ and $\mathrm{B}$. This sensitivity test was carried out using Archie's parameters calculated by common values technique and 3D technique. The average water saturation values shown in Table 6 clearly indicate the effect of saturation exponent on the water saturation computation in wells A and B using common values and 3D techniques. Figure 7a shows water saturation profiles with variable saturation exponents using common values technique and Figure $7 \mathrm{~b}$ shows saturation profiles using 3D technique for well A. Water saturation profiles with the two techniques (common values and 3D) are shown in Figures $8 \mathrm{a}$ and $8 \mathrm{~b}$ for well $\mathrm{B}$. The comparison between Figures 7 and 5 for well A and Figures 8 and 6 for well B demonstrates clearly the increasing trend of water saturation profiles as saturation exponent increases. These computed 

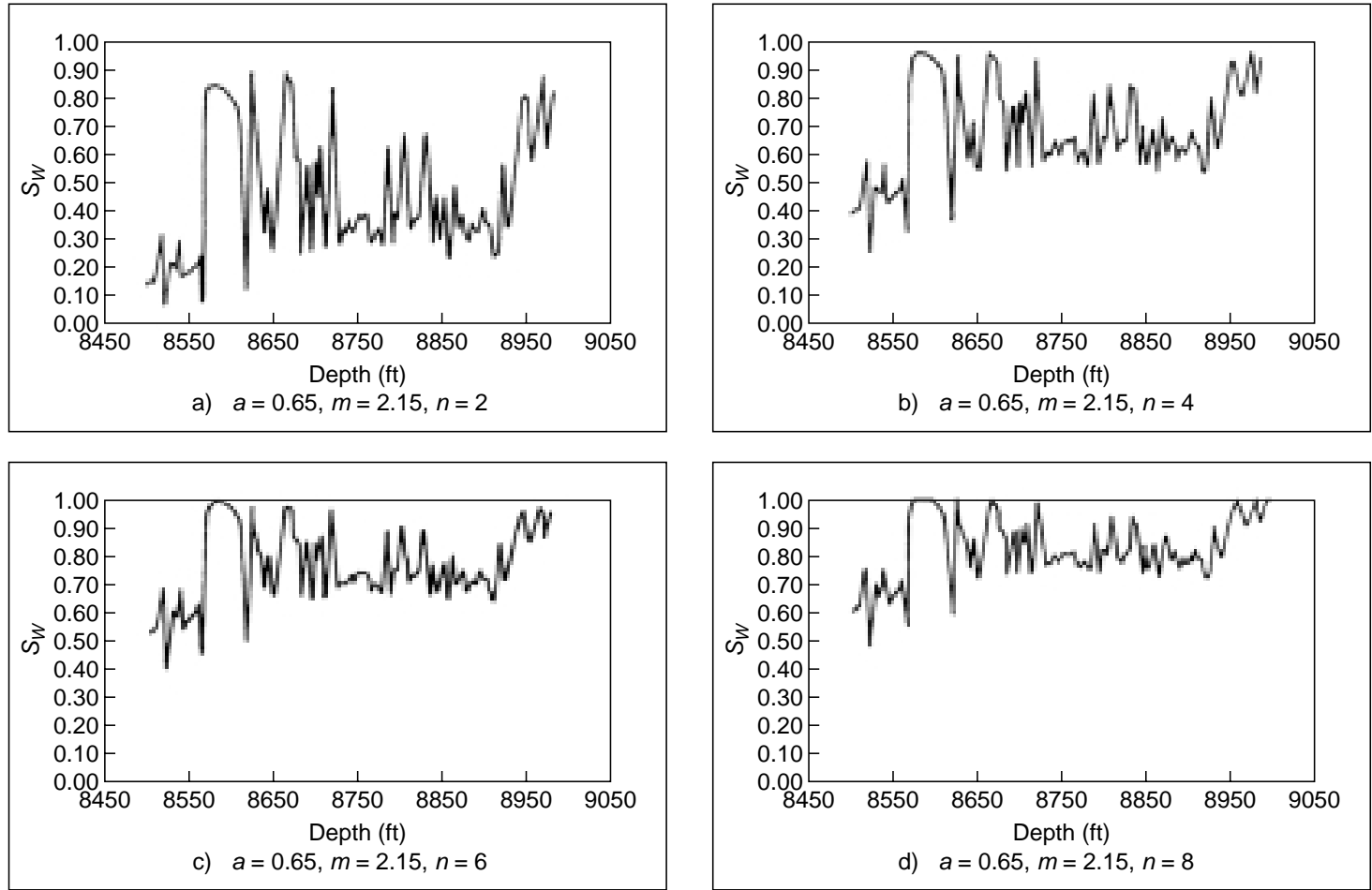

Figure 7a

Change of water saturation with change of water saturation exponent (conventional technique) for well A.

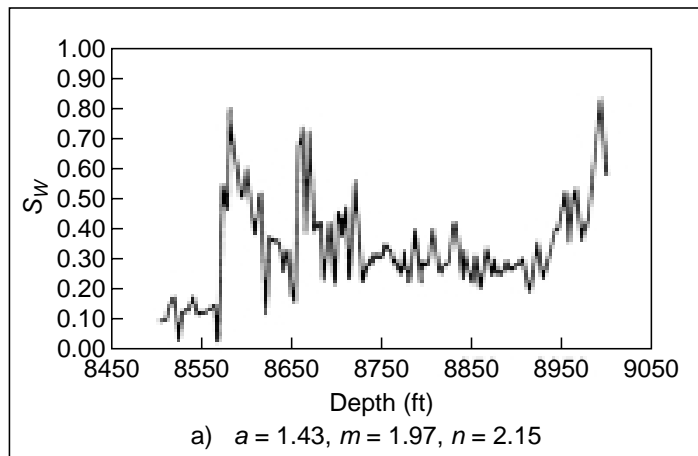

a) $a=1.43, m=1.97, n=2.15$

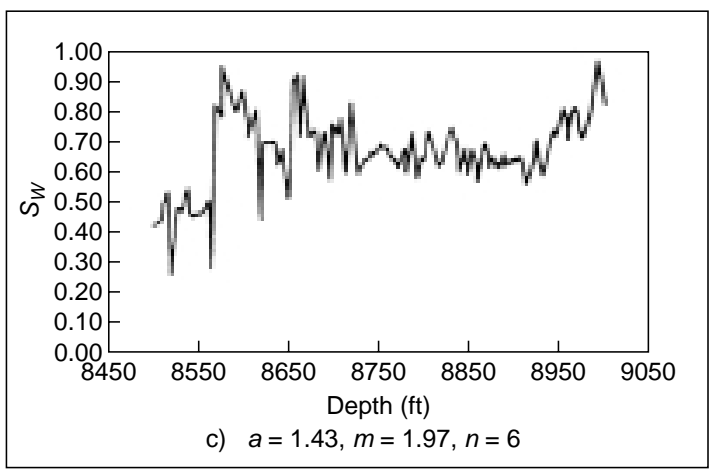

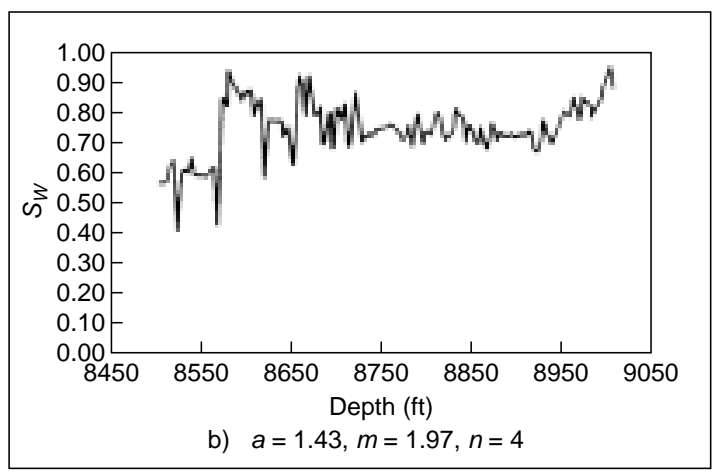

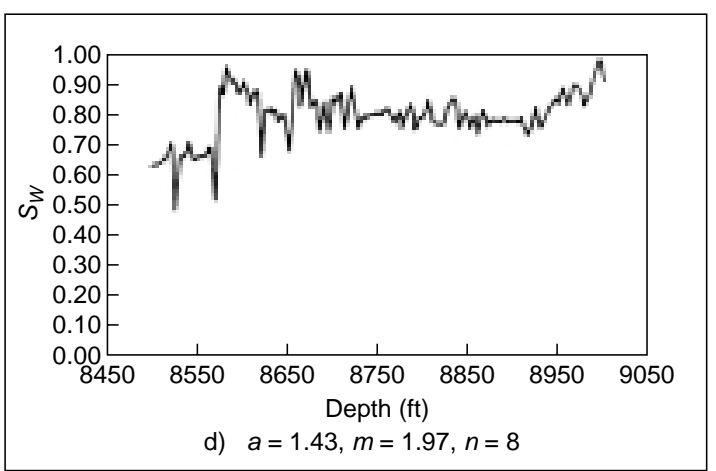

Figure $7 \mathrm{~b}$

Change of water saturation with change of water saturation exponent (3D technique) for well A. 

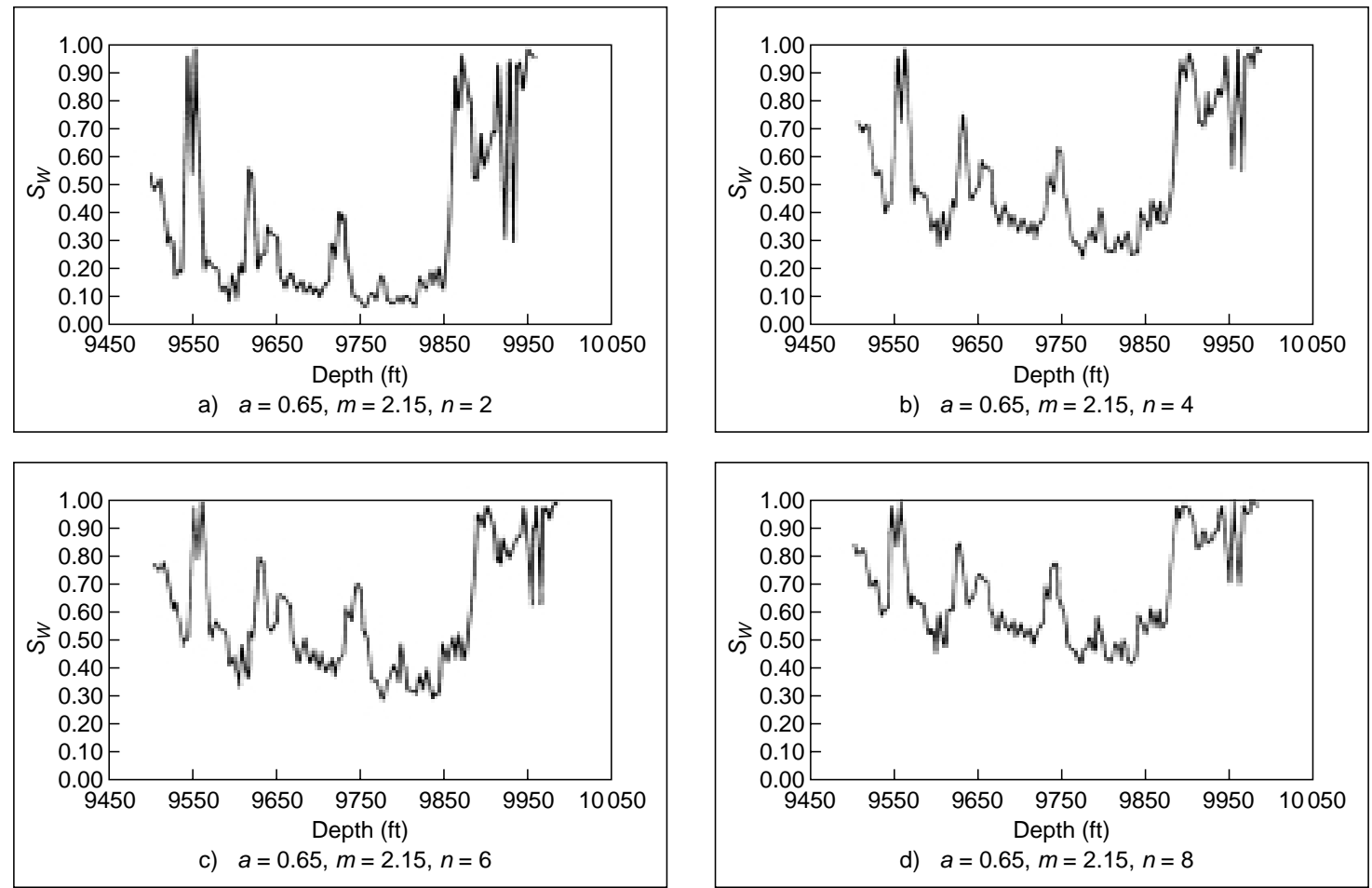

Figure 8a

Change of water saturation with change of water saturation exponent (conventional technique) for well B.
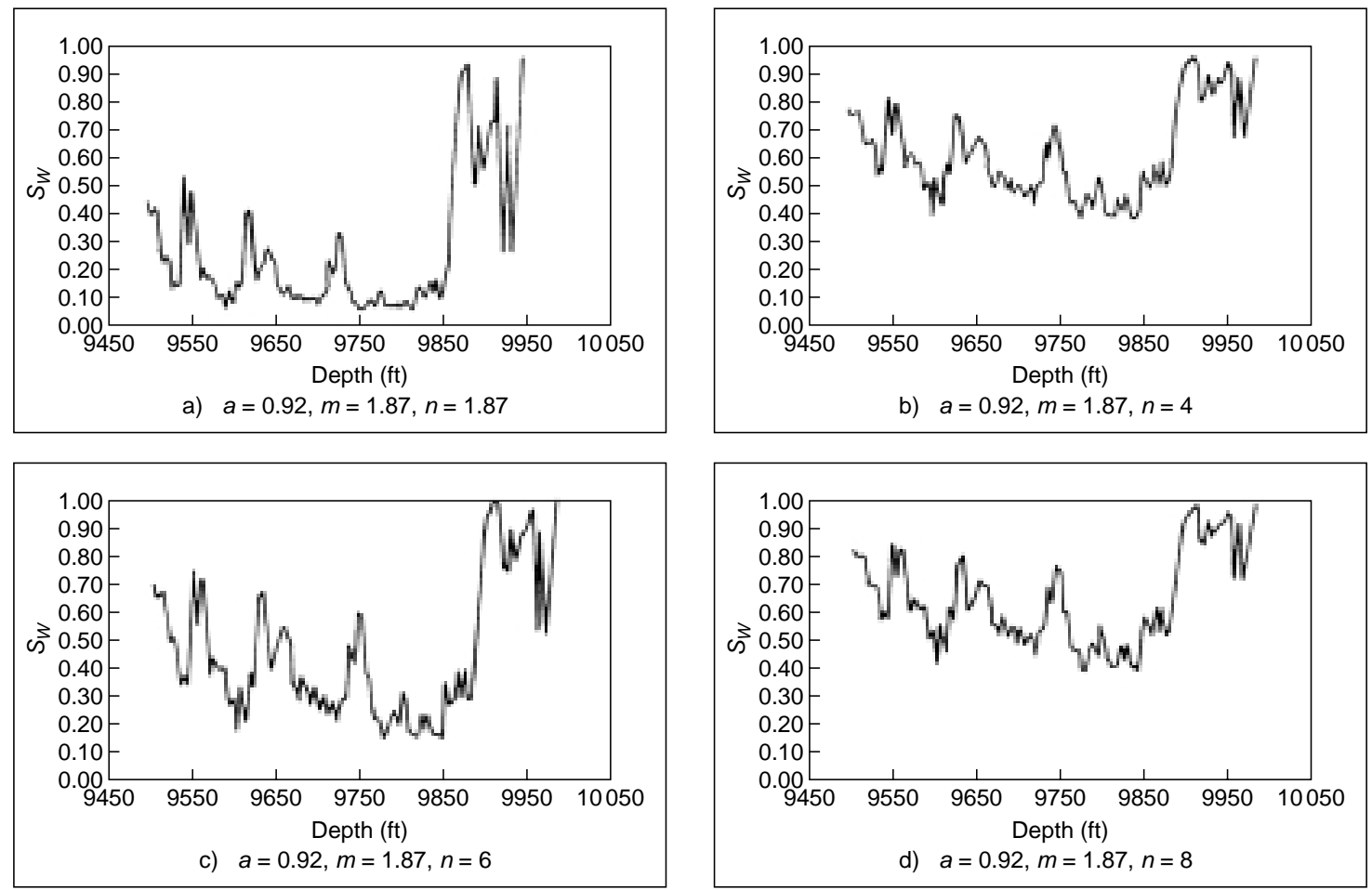

Figure $8 b$

Change of water saturation with change of water saturation exponent (3D technique) for well B. 
water saturations for well A and B showed an exponential increase of water saturation with the increase of saturation exponent. It may follow the following relations between the average water saturation and saturation exponent using all points in Table 6 of wells A and B.

$$
S_{w}=0.634 \log 1.779 n \text { for } 3 \mathrm{D} \text { technique }
$$

$S_{w}=0.794 \log 1.171 n$ for common values technique

It is observed that the effect of saturation exponent on water saturation computation is more significant at lower water saturation values than at higher values. From the average water saturation values in Table 6 and water saturation profiles in Figures 7 and 8, we can conclude that the common values technique is more sensitive than the $3 \mathrm{D}$ technique to changes in the saturation exponent. This sensitivity reflects the exigency for an accurate saturation exponent determination to properly compute the water saturation either by Archie's formula or by the shaly water saturation model.

\section{CONCLUSIONS}

Archie's parameters have been determined by four techniques; common values, conventional, CAPE and 3D. From the analysis and application of these techniques in the computation of water saturation either in clean sands or shaly sands, the following conclusions may be drawn:

- Conventional technique optimises the two functions $\mathrm{F}$ versus $\phi$ and $R_{t}$ vs. $S_{w}$ rather than water saturation values. While CAPE technique confirms that the quantity to be optimised is not the two functions but rather the water saturation.

- The 3D technique provides simultaneously the values of Archie's parameters from standard resistivity measurements on core samples. Unlike the conventional method, which ignored the values of $S_{w}<1.0$ in the determination of $a$ and $m$, the 3D method uses all data of $S_{w}$ points.

- 3D technique answers the controversial question of whether tortuosity factor, $a$, should be fixed at unity or not. It gives directly $a, m$ and $n$, and thereby, it is recommended to consider the case of the three variables $a$, $m$ and $n$.

- For applications where the highest possible accuracy in hydrocarbon saturation is required, it is recommended to use the 3D technique, unless, there are adverse conditions as mentioned in the text.

- The saturation exponent ( $n$ ) has a great effect on water saturation computation. The saturation exponent is affected by many factors such as reservoir rock wettability and the presence of certain authogenic clays that may promote oil wet characteristics. Therefore, it is recommended to calculate the saturation exponent considering reservoir wettability conditions. On the side, there is no a significant effect of wettability alteration on the value of formation resistivity factor, $F$.

\section{REFEREN CES}

1 Archie, G.E. (1942) Electrical Resistivity Log as an Aid in Determining Some Reservoir Characteristics. Trans., AIME, 146, 54-62.

2 Atkins, ER. and Smith, G.H. (1961) The Significance of Particle Shape in Formation Resistivity Factor-Porosity Relationship. JPT, March, 285-291.

3 Borai, A.M. (1987) A New Correlation for the Cementation Factor in Low-Porosity Carbonates. SPE Formation Evaluation, December, 495-498.

4 Winsauer, W.O. and McCardell, W.M. (1954) Ionic-Double Layer Conductivity in Reservoir Rocks. Trans, AIME, 17-23.

5 Maute, R.E., Lyle, W.D. and Sprunt, E. (1992) Improved Data-Analysis Method Determines Archie Parameters from Core Data. JPT, January, 103-107.

6 Ransom, R.C. (1984) A Contribution Toward a Better Understanding of the Modified Archie Formation Resisivity Factor Relationship. The Log Analyst, March-April, 7-12.

7 Shouxiang, Ma. and Xiaoyun, Zh. (1994) Determination of Archie's Cementation Exponent from Capillary Pressure Measurements. Trans., Intr. Symposium on Well Logging Technology, X'ian, China, 83-103.

8 Sweeney, S.A. and Jenning, H.Y. (1960) The Electrical Resistivity of Preferentially Water-Wet and Preferentially Oil-Wet Carbonate Rock, Producers Monthly, Schlumberger, 24, 29-32.

9 Worthington, P.E. and Pallet, N. (1992) Effect of Variable Saturation Exponent on the Evaluation of Hydrocarbon Saturation. SPE Formation Evaluation, December, 331-336.

10 Hamada, G.M., Assal, A.M. and Ali, M.A (1996) Improved Technique to Determine Archie's Parameters and Consequent Impact on the Exactness of Hydrocarbon Saturation Values. SCA, Paper 9623, presented at Intl. Symposium of SCA, Sept. 8-10, Montpellier, France.

11 Doll, H.G. and Martin, M. (1954) How to Use Electric Log Data to Determine Maximum Producible Oil Index. Oil and Gas J., July, 77-82.

12 Poupon, A., Loy, M.E. and Tixier, M.P. (1954) A Contribution to An Electrical Log Interpretation in Shaly Sands. JPT, June, 354-366.

13 Hossin, A. (1960) Calcul des saturations en eau par la méthode du ciment argileux (formule d'Archie généralisée). Bulletin AFTP, 125-128.

14 Dresser Atlas (1982) Well Logging and Interpretation Techniques, Dresser Atlas Ltd.

Final manuscript received in September 2002 